\title{
Author Correction: Characterization of Split Fluorescent Protein Variants and Quantitative Analyses of Their Self-Assembly Process
}

\author{
Tuğba Köker, Anthony Fernandez \& Fabien Pinaud (1) \\ Correction to: Scientific Reports https://doi.org/10.1038/s41598-018-23625-7, published online 28 March 2018
}

This Article contains errors in Table 1. E124V was incorrectly included in the 'Substitutions' column for flCFP2 and sCFP2. The correct Table 1 appears below.

As a result, in the Results section under the subheading 'Point mutations to generate full-length and split-GFP, split-YFP and split-CFP variants',

"We also produced two flCFP/sCFP variants" ${ }^{21}$, flCFP1/sCFP1 (D19E/D21E/Y66W/E124V/ H148D/T205S) and flCFP2/sCFP2 (D19E/D21E/Y66W/E124V/H148D/V167I/T205S) (Table 1). Both variants contain the Y66W substitution that alters the GFP spectral properties to CFP ${ }^{25}$, the H148D and T205S substitution that improve CFP quantum yield (QY) ${ }^{26,27}$, a E124V substitution, which allows for faster folding rates in superfolder GFP Gs $^{28}$ well as D19E and D21E substitutions that provide faster initial rate of cyan fluorescence appearance compared to sCFP carrying only Y66W and T205S mutations ${ }^{21}$. flCFP2/sCFP2 variants also contain a V167I substitution, which provides increased cyan fluorescence brightness ${ }^{21}$."

should read:

"We also produced two flCFP/sCFP variants ${ }^{21}$, flCFP1/sCFP1 (D19E/D21E/Y66W/E124V/ H148D/T205S) and flCFP2/sCFP2 (D19E/D21E/Y66W/H148D/V167I/T205S) (Table 1). Both variants contain the Y66W substitution that alters the GFP spectral properties to CFP ${ }^{25}$, the H148D and T205S substitutions that improve CFP quantum yield (QY) ${ }^{26,27}$, and the D19E and D21E substitutions that provide faster initial rate of cyan fluorescence appearance compared to SCFP carrying only Y66W and T205S mutations ${ }^{21}$. The flCFP1/sCFP1 variants contain a E124V substitution, which reportedly allows for faster folding rates in superfolder $\mathrm{GFP}^{28}$, while the flCFP2/sCFP2 variants contain a V167I substitution, which provides increased cyan fluorescence brightness ${ }^{21}$."

In the Results section under the subheading 'Spectral properties of full-length FP and split-FP variants',

"The additional V167I substitution in flCFP2/sCFP2 did not induce significant spectral changes (Table 1, Fig. la,b)."

should read:

"The additional V167I substitution and the absence of E124V in flCFP2/sCFP2 did not induce significant spectral changes (Table 1, Fig. 1a,b)."

In the Results section under the subheading 'Photobleaching characteristics of split-GFP variants',

"Concerning the photobleaching rates $\left(k_{3}\right)$, the V167I mutation in sGFP1 slows down irreversible photobleaching by $15 \%$ compared to sGFPori."

should read: 


\begin{tabular}{|c|c|c|c|c|c|c|c|c|c|c|}
\hline & \begin{tabular}{l|} 
Exc. $\lambda$ \\
$(\mathbf{n m})$
\end{tabular} & $\begin{array}{l}\text { Em. } \lambda \\
(\mathbf{n m})\end{array}$ & $\begin{array}{l}\varepsilon \\
\left(\mathrm{M}^{-1} \mathrm{~cm}^{-1}\right)\end{array}$ & $\Phi$ & Brightness & $\begin{array}{l}\tau_{1} \\
(n s)\end{array}$ & $\begin{array}{l}A_{1} \\
(\%)\end{array}$ & $\begin{array}{l}T_{2} \\
(\mathbf{n s})\end{array}$ & $\begin{array}{l}A_{2} \\
(\%)\end{array}$ & Substitutions \\
\hline flGFPori & 485 & 507 & 37,700 & 0.66 & 24,880 & 2.46 & 100 & - & - & $\begin{array}{l}\text { S30R, N39I, F64L, S65T, F99S, T105K, E111V, I128T, Y145F, M153T, } \\
\text { V163A, K166T, I167V, I171V, S205T, A206V, K221H, F223Y, T225N }\end{array}$ \\
\hline flGFP1 & 485 & 507 & 33,800 & 0.75 & 25,350 & 2.5 & 100 & - & - & ${ }^{4} \mathrm{~V} 167 \mathrm{~T}$ \\
\hline flGFP2 & 491 & 510 & 38,200 & 0.77 & 29,410 & 2.77 & 100 & - & - & ${ }^{\psi}$ V167T, S72A \\
\hline flGFP3 & 482 & 508 & 39,900 & 0.68 & 27,130 & 2.67 & 100 & - & - & ${ }^{\psi}$ V167T, S72A, N149K \\
\hline flYFP1 & 511 & 522 & 68,300 & 0.61 & 41,660 & 2.76 & 100 & - & - & ${ }^{\psi}$ T65G, T203Y, T205S \\
\hline flYFP2 & 509 & 522 & 38,200 & 0.54 & 20,630 & 1.13 & 29 & 3.14 & 71 & ${ }^{\psi}$ T65L, T203Y, T205S \\
\hline flYFP3 & 515 & 526 & 37,100 & 0.51 & 18,920 & 0.72 & 37 & 3.59 & 63 & ${ }^{4}$ T203Y, T205A \\
\hline flCFP1 & 435 & 476 & 20,400 & 0.41 & 8,360 & 0.98 & 62 & 2.57 & 38 & ${ }^{\psi}$ D19E, D21E, Y66W, E124V, H148D, T205S \\
\hline flCFP2 & 436 & 476 & 21,300 & 0.42 & 8,950 & 0.97 & 27 & 2.76 & 73 & ${ }^{\psi}$ D19E, D21E, Y66W, H148D, V167I, T205S \\
\hline sGFPori & 485 & 508 & 37,700 & 0.59 & 22,240 & 2.29 & 100 & - & - & $\begin{array}{l}\text { S30R, N39I, F64L, S65T, F99S, T105K, E111V, I128T, Y145F, M153T, } \\
\text { V163A, K166T, I167V, I171V, S205T, A206V }\end{array}$ \\
\hline sGFP1 & 485 & 508 & 33,800 & 0.62 & 20,960 & 2.34 & 100 & - & - & ${ }^{8} \mathrm{~V} 167 \mathrm{~T}$ \\
\hline sGFP2 & 491 & 510 & 38,200 & 0.67 & 25,730 & 2.64 & 100 & - & - & ${ }^{8} \mathrm{~V} 167 \mathrm{~T}, \mathrm{~S} 72 \mathrm{~A}$ \\
\hline sGFP3 & 480 & 508 & 39,900 & 0.29 & 11,600 & 2.5 & 100 & - & - & ${ }^{8} \mathrm{~V} 167 \mathrm{~T}, \mathrm{~S} 72 \mathrm{~A}, \mathrm{~N} 149 \mathrm{~K}$ \\
\hline sYFP1 & 510 & 523 & 68,300 & 0.44 & 30,100 & 2.62 & 100 & - & - & ${ }^{8} \mathrm{~T} 65 \mathrm{G}, \mathrm{T} 203 \mathrm{Y}, \mathrm{T} 205 \mathrm{~S}$ \\
\hline sYFP2 & 509 & 522 & 38,200 & 0.09 & 3,440 & 0.74 & 22 & 2.9 & 78 & ${ }^{8} \mathrm{~T} 65 \mathrm{~L}, \mathrm{~T} 203 \mathrm{Y}, \mathrm{T} 205 \mathrm{~S}$ \\
\hline sYFP3 & 515 & 524 & 37,100 & 0.35 & 12,990 & 0.47 & 40 & 3.28 & 60 & ${ }^{8} \mathrm{~T} 203 \mathrm{Y}, \mathrm{T} 205 \mathrm{~A}$ \\
\hline sCFP1 & 433 & 475 & 20,400 & 0.18 & 3,670 & 0.81 & 40 & 2.4 & 60 & ${ }^{8}$ D19E, D21E, Y66W, E124V, H148D, T205S \\
\hline sCFP2 & 433 & 476 & 21,300 & 0.23 & 4,900 & 0.64 & 25 & 2.52 & 75 & ${ }^{8}$ D19E, D21E, Y66W, H148D, V167I, T205S \\
\hline
\end{tabular}

Table 1. Fluorescence properties of full-length and split fluorescent protein variants. ع: Molar extinction coefficient, $\Phi$ : Quantum yield, $\psi$ : Additional substitutions in flGFPori, $\delta$ : Additional substitutions in sGFPori, $\tau_{1} \& \tau_{2}$ : Fluorescence lifetimes $1 \& 2$ for two-photon $870 \mathrm{~nm}$ excitation, $A_{1} \& A_{2}$ : Fractions of fluorescence lifetimes $1 \& 2$.

"Concerning the photobleaching rates $\left(k_{3}\right)$, the V167T mutation in SGFP1 slows down irreversible photobleaching by $15 \%$ compared to sGFPori."

In the Results section under the subheading 'Folding kinetics of full-length FP variants',

"Interestingly, the additional V167I mutation in flCFP2 dramatically improves both $k_{\text {fold } 1}\left(1.955 \mathrm{~min}^{-1}\right)$ and $k_{\text {fold } 2}$ $\left(0.195 \mathrm{~min}^{-1}\right)$ compared to flCFP1."

should read:

"Interestingly, the additional V167I mutation and the absence of E124V in flCFP2 dramatically improve both $k_{\text {fold } 1}$ $\left(1.955 \mathrm{~min}^{-1}\right)$ and $k_{\text {fold } 2}\left(0.195 \mathrm{~min}^{-1}\right)$ compared to flCFP1."

In the Results section under the subheading 'Chromophore maturation kinetic of full-length FP variants',

"The flCFP variants flCFP1 $\left(k_{\text {mat }}: 0.011 \mathrm{~min}^{-1}\right)$ and flCFP2 $\left(k_{\text {mat }}: 0.012 \mathrm{~min}^{-1}\right)$ have maturation rate constants similar to that previously reported for ECFP $\left(k_{\text {mat }}: 0.0096 \mathrm{~min}^{-1}\right)^{55}$ and the V167I substitution in flCFP2 does not impact the maturation rate (Fig. 3c)."

should read:

"The flCFP variants flCFP1 $\left(k_{\text {mat }}: 0.011 \mathrm{~min}^{-1}\right)$ and flCFP2 $\left(k_{\text {mat }}: 0.012 \mathrm{~min}^{-1}\right)$ have maturation rate constants similar to that previously reported for ECFP $\left(k_{\text {mat }}: 0.0096 \mathrm{~min}^{-1}\right)^{55}$ and neither the presence of E124V in flCFP1 nor that of V167I in flCFP2 impact the maturation rate (Fig. 3c)."

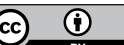

Open Access This article is licensed under a Creative Commons Attribution 4.0 International License, which permits use, sharing, adaptation, distribution and reproduction in any medium or format, as long as you give appropriate credit to the original author(s) and the source, provide a link to the Creative Commons license, and indicate if changes were made. The images or other third party material in this article are included in the article's Creative Commons license, unless indicated otherwise in a credit line to the material. If material is not included in the article's Creative Commons license and your intended use is not permitted by statutory regulation or exceeds the permitted use, you will need to obtain permission directly from the copyright holder. To view a copy of this license, visit http://creativecommons.org/licenses/by/4.0/.

(c) The Author(s) 2019 